\title{
Tumoral form of aspergillosis
}

in central nervous system (cerebral aspergilloma):

- Eberval Gadelha Figueiredo

- Erich Fonoff

- Marcos Gomes

- Emílio Macedo

- Raul Marino Júnior

\section{case report}

\author{
Division of Neurosurgical Clinic, Hospital das Clinicas, Faculdade de \\ Medicina, Universidade de São Paulo, São Paulo, Brazil
}

\section{. . . . . INTRODUCTION}

Aspergillosis of the central nervous system is an uncommon infection, mainly occurring in immunocompromised patients. There are various clinical presentation forms of this infection: aseptic ${ }^{1,2}$ and persistent meningitis, mycotic aneurysms, ${ }^{2}$ ischemic and hemorrhagic infarcts and the tumor-like form or aspergilloma. In this article we present a case of a patient with cerebral aspergilloma.

\section{$\ldots \ldots \ldots$ CASE REPORT}

A forty-two-year-old woman was brought to the emergency department. She had diabetes that was under poor control and she had been having progressive headaches over a three-week period. Her mental state was impaired, and she had right-sided body weakness and loss of vision. The neurological examination showed right hemiparesis, decreased visual acuity in the right eye and blindness in the left eye. There was no eye deviation or anisocoria. Further examination revealed comprehension aphasia, thus accounting for the impairment of her mental state.

A computed tomographic scan revealed a tumor-like lesion with high density and moderate mass effect on the anterior left temporal lobe with edema in the surrounding area. It appeared to have moderate heterogeneous enhancement with iodide contrast solution. Magnetic resonance imaging showed also a mass over the left temporal lobe in its mesial aspects and infiltrating the left cavernous sinus, with a high signal in the T1-weighted series (Figure 1). The surrounding edema was best observed in the T2 series (Figure 2).

After compensating for her diabetes, she underwent surgery by means of temporoparietal craniotomy. The lesion encountered had a light yellowish color, hard consistency and very significant bleeding when manipulated. The intraoperative pathological examination revealed fungal hyphae. The operation became protracted and resection was only partially performed.

During the postoperative period, she was given intravenous amphotericin B. She required long treatment due to postoperative fungal meningitis that was probably elicited by the surgical manipulation.

\section{$\ldots \ldots \ldots . . . . .$. DISCUSSION $_{0}$}

Cerebral aspergillosis is an infrequent medical condition, but it is still a potentially fatal disease. However, it has become more frequently diagnosed because of high rates of suspicion among immunocompromised patients such as those with transplants and HIVpositive or aids patients, who show higher incidence of the condition. In a series of 1,730 transplanted patients, 60 were neurologically compromised and $18.3 \%$ of these had aspergilloma. ${ }^{2} \mathrm{~A}$ few more cases with the tumoral form in immunocompromised patients have been reported by Shuper. ${ }^{3}$

The lungs are probably the entry portal. However, isolated central nervous system aspergillosis (no detectable pulmonary disease) has already been reported. ${ }^{4}$ The prognosis in such patients is very poor even with surgical and anti-fungal treatment, especially when there is an association with

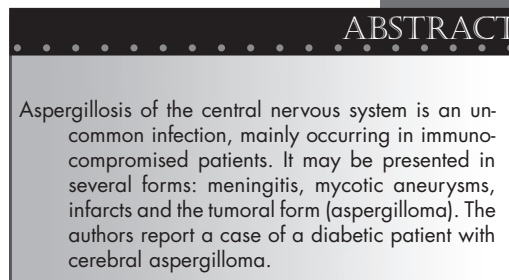

KEY WORDS: Aspergillosis. Diabetes mellitus. Aspergillus. Central nervous system neoplasms. 
other bacteria or infections. ${ }^{1,4}$

Aspergilloma is even rarer in patients who are apparently immunocompetent, although all cases described have had associated diseases such as diabetes mellitus or unhealthy habits like drug abuse. . $^{1,4}$

Diagnosis of aspergilloma in immunocompetent patients remains difficult because medical staff rarely suspects this condition.
Although such patients have much better prognosis than for immunocompromised patients, the diagnosis is frequently missed or delayed. ${ }^{3}$

Neuroimaging gives some backing for considering such a diagnosis, although it does not bring any specific findings to light. The radiological findings in aspergilloma cases are the same as for brain abscesses and may have an appearance similar to that of many tumors. There is frequently a ring-like enhancement when contrast medium is injected. With magnetic resonance imaging, it appears as a tumoral lesion with a low signal in the T1-weighted series, with variable edema on the lesion periphery. Routine analysis of cerebrospinal fluid does not help in elucidating the etiology.

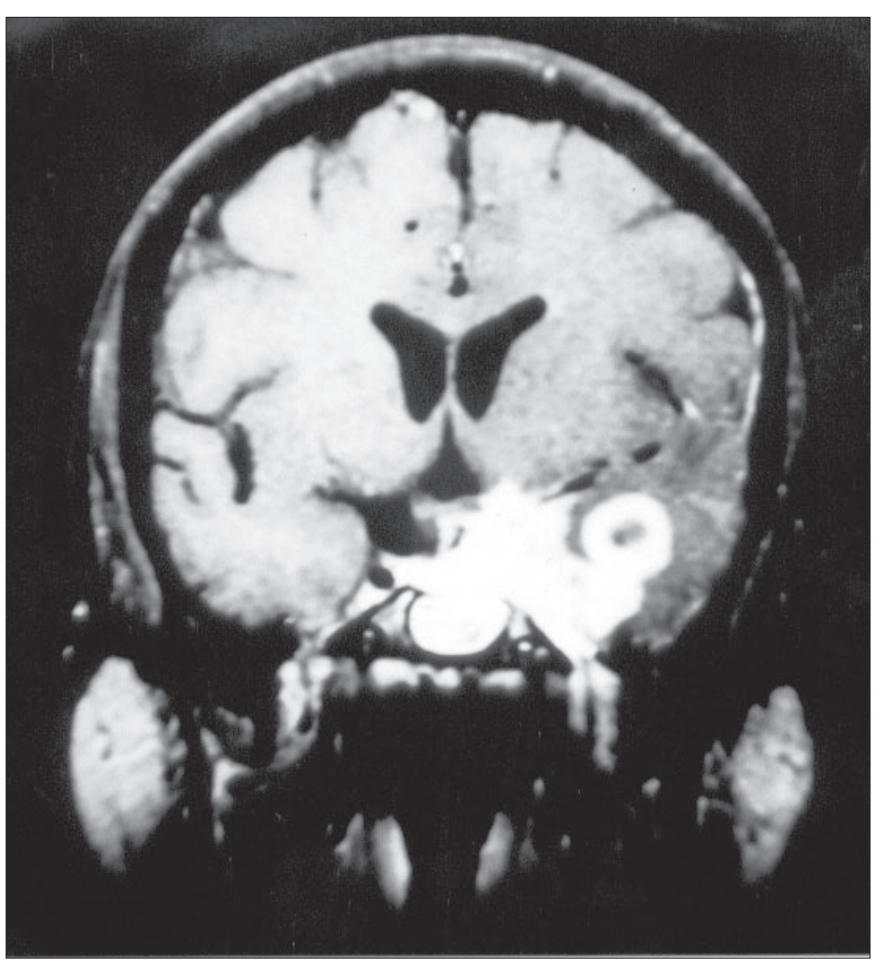

Figure 1. Coronal magnetic resonance imaging of the brain in the T1-weighted series after gadolinium injection, showing a lesion over the left temporal lobe in its mesial aspect and infiltrating the left cavernous sinus, with high signal.

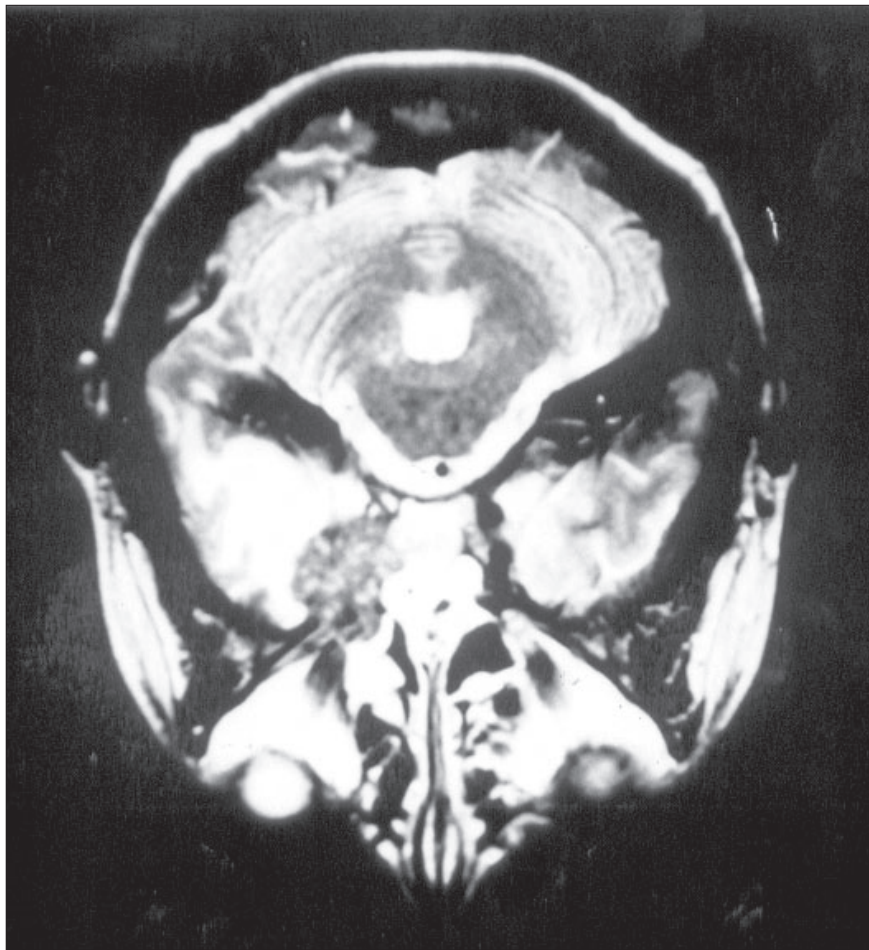

Figure 2. Magnetic resonance imaging of the brain in the T2 series, showing left temporal lobe edema. 
1. Boes B, Bashir R, Boes C, Hahn F, McConnell JR, McComb R. Central nervous system aspergillosis. Analysis of 26 patients. J Neuroimaging 1994;4(3):123-9.

2. Breneman E, Colford JM. Aspergillosis of the CNS pre- senting as aseptic meningitis. Clin Infect Dis 1992; 15(4):737-8

3. Shuper A, Levitsky HI, Cornblath DR. Early invasive CNS aspergillosis. An easily missed diagnosis. Neuroradiology
1991;33(2):183-5

4. Walsh TJ, Hier DB, Caplan LR. Aspergillosis of the central nervous system: clinicopathological analysis of 17 patients. Ann Neurol, 1985;18(5):574-82.
. PU⿴囗十.ISHING INFORMATION.

Eberval Gadelha Figueiredo, MD. Assistant neurosurgeon, Clinical Neurosurgery Division, Hospital das Clínicas, Faculdade de Medicina, Universidade de São Paulo, São Paulo, Brazil.

Erich Fonoff, MD. Resident doctor, Clinical Neurosurgery Division, Hospital das Clínicas, Faculdade de Medicina, Universidade de São Paulo, São Paulo, Brazil.

Marcos Gomes, MD. Assistant neurosurgeon, Clinical Neurosurgery Division, Hospital das Clínicas, Faculdade de Medicina, Universidade de São Paulo, São Paulo, Brazil.

Emílio Macedo, MD. Resident doctor, Clinical Neurosurgery Division, Hospital das Clínicas, Faculdade de Medicina, Universidade de São Paulo, São Paulo, Brazil.

Raul Marino Júnior, MD. Professor, Clinical Neurosurgery Division, Hospital das Clínicas, Faculdade de Medicina, Universidade de São Paulo, São Paulo, Brazil.

\section{Sources of funding: None \\ Conflict of interest: None}

Date of first submission: April 22, 2003

Last received: May 26, 2003

Accepted: May 30, 2003

\section{Address for correspondence:}

Eberval Gadelha Figueiredo

3848, N 3rd Avenue

Apt. 3069

Phoenix - Arizona 85013

USA

E-mail:ebergadelha@msn.com

COPYRIGHT @ 2003, Associação Paulista de Medicina

RESUMO

\section{Aspergiloma cerebral: Relato de caso}

Aspergilose do sistema nervoso central é uma infecção rara, acometendo principalmente pacientes imunossuprimidos. Clinicamente pode se apresentar sob várias formas: meningite, aneurisma micótico, infartos cerebrais e como lesão tumoral (aspergiloma). Os autores apresentam o caso de um paciente diabético com aspergiloma cerebral.

PALAVRAS-CHAVE: Aspergilose. Diabetes mellitus. Aspergillus. Tumores cerebrais. Sistema nervoso central. 